\title{
Patterns of perception toward influenza pandemic among the front-line responsible health personnel in southern Thailand: a $\mathbf{Q}$ methodology approach
}

\author{
Tapanan Prateepko* and Virasakdi Chongsuvivatwong
}

Address: Epidemiology Unit, Faculty of Medicine, Prince of Songkla University, Hatyai, Thailand

Email: Tapanan Prateepko* - ksawa98@hotmail.com; Virasakdi Chongsuvivatwong - cvirasak@medicine.psu.ac.th

* Corresponding author

Published: 28 May 2009

BMC Public Health 2009, 9:161 doi:10.1/86/147|-2458-9-161

This article is available from: http://www.biomedcentral.com/|47/-2458/9//6I

(C) 2009 Prateepko and Chongsuvivatwong; licensee BioMed Central Ltd.

This is an Open Access article distributed under the terms of the Creative Commons Attribution License (http://creativecommons.org/licenses/by/2.0), which permits unrestricted use, distribution, and reproduction in any medium, provided the original work is properly cited.

\begin{abstract}
Background: Thailand has joined the World Health Organization effort to prepare against a threat of an influenza pandemic. Regular monitoring on preparedness of health facilities and assessment on perception of the front-line responsible health personnel has never been done. This study aimed to document the patterns of perception of health personnel toward the threat of an influenza pandemic.
\end{abstract}

Methods: Q methodology was applied to a set of 385 health personnel in charge of influenza pandemic preparedness in the three southernmost provinces of Thailand. Subjects were asked to rank 33 statements about various issues of influenza pandemic according to a pre-designed score sheet having a quasi-normal distribution on a continuous 9-point bipolar scale ranging from -4 for strongly disagree to +4 for strongly agree. The $Q$ factor analysis method was employed to identify patterns based on the similarity and dissimilarity among health personnel.

Results: There were three main patterns of perception toward influenza pandemic with moderate correlation coefficients between patterns ranging from 0.37 to 0.55 . Pattern I, health personnel, which we labeled pessimistic, perceived themselves as having a low self-efficacy. Pattern II, which we labeled optimistic, perceived the threat to be low severity and low vulnerability. Pattern III, which we labeled mixed, perceived low self-efficacy but low vulnerability. Across the three patterns, almost all the subjects had a high expectancy that execution of recommended measures can mitigate impacts of the threat of an influenza pandemic, particularly on multi-measures with high factor scores of 4 in all patterns. The most conflicting area was vulnerability on the possible impacts of an influenza pandemic, having factor scores of high (3), low (-4), and neutral (0) for patterns I, II, and III, respectively.

Conclusion: Strong consistent perceptions of response efficacy against an influenza pandemic may suggest a low priority to convince health personnel on the efficacy of the recommended measures. Lack of self-efficacy in certain sub-groups indicates the need for program managers to improve selfconfidence of health personnel to participate in an emergency response. 


\section{Background}

An influenza pandemic is a significant natural health threat that has periodically occurred over the past 300 years [1]. Its severe impacts to global human health, healthcare service, society, and economy were evidently documented during the previous pandemics [2,3]. For a coming one, influenza experts have agreed that this threat is inevitable and possibly imminent [4]. If the next pandemic occurs, it is expected that $20 \%$ of the global population will become ill, nearly 30 million will be hospitalized and a quarter of these would die within a few months of its attack [5]. To mitigate the impacts of this threat, the World Health Organization (WHO) has recommended that all countries should consider this threat as very important and urged them to make preparations a high national priority.

Thailand occasionally has had serious outbreaks of avian influenza A (H5N1) since early 2004, in both poultry and humans. In response to these outbreaks and a possible future influenza pandemic, the national committee on avian influenza control and influenza pandemic preparedness has issued a national strategic plan for influenza pandemic preparedness.

Beyond preparedness, the perception of each individual is also a fundamental factor that contributes to the spread, prevention, and control of infectious diseases. For example, during the Severe Acute Respiratory Syndrome (SARS) epidemics, the perceptions toward this disease had an effect on the preventive health behaviors (e.g., hand hygiene, mask wearing) and that consequently contributed to containing the outbreaks [6-8]. For a current threat of an influenza pandemic, sporadic perception surveys among health workers have been done in developed countries [9-12]. Yet this issue has not been explored in developing countries, particularly in the southeast Asian region where it is more likely to be a source of the next pandemic [13].

Southern Thailand experienced a probable SARS case in 2003, but there has been no reported case of avian influenza A (H5N1) in both poultry and human. However, the region faces a serious problem of ethnic violence. This unrest has led to the loss of over 2,600 lives and more than 7,000 injuries in the past 5 years. It is possible that the local health systems may have deteriorated due to the unrest leading to loosening of preparedness against the threat of an influenza pandemic. We have therefore conducted a study to investigate the preparedness. The current report is confined to perceptions related to the threat of an influenza pandemic with the objective to document the patterns of perception of health personnel toward this threat in southern Thailand. As health personnel are key persons for influenza pandemic preparedness and con- trol, it is hoped that understanding their patterns of perception will allow control programs to properly improve the training. It may also be useful for other developing countries where an influenza pandemic is a serious threat, but the personnel are not fully prepared.

\section{Methods \\ Study design}

Q methodology, which basically originated from the theory of factor analysis [14] was applied. While conventional factor analysis is used in scale development and tries to group items or variables, Q method tries to group subjects. Therefore, people of the same group or having the same factor will have a similar pattern of chosen statements. The implication would be that it would be easy to put people of the same factor into the same intervention program. This method was taken into our study because this is a scientific and systematic study of human subjectivity, involving perceptions, attitudes, and opinions $[15,16]$. Furthermore, it is also unique since it mixes the strong points of both qualitative and quantitative research techniques, compared to traditional surveys $[17,18]$.

In doing $\mathrm{Q}$, the flow of communication surrounding the study topic (concourse) is firstly formed to get a wide range of ideas toward that topic. This is generally collected from various sources (e.g., scientific papers, books, news, interviews, focus group discussions, etc.). It is commonly presented in the form of statements. Afterward, a Q sample (a representative set of statements) is selected from the concourse and developed to be more meaningful, which represents various issues of the study topic and eventually is compiled into the instrument. The study subjects are then asked to rank the representative statements and place them into a score sheet, which is designed in a continuous scale ranging from strongly disagree to strongly agree, following a standardized instruction based on the judgment of each subject. This is known as the $\mathrm{Q}$ sorting procedure. The sheets that are completely ranked by each subject (Qsort) are finally correlated and analyzed by Q (subjectwise) factor analysis, and the factors are then interpreted.

In our study, 100 statements on various issues of an influenza pandemic were initially gathered from scientific articles, newsletters, and books to form a concourse. The protection motivation theory (PMT) was used as a basis for grouping and developing the statements into four domains: perceived severity, perceived vulnerability, perceived response efficacy, and perceived self-efficacy, by refining, clarifying, and combining the raw statements to be more meaningful and more understandable. To catch various aspects of an influenza pandemic and keeping the total number of the statements suitably manageable by our subjects, we included eight refined statements in each of such four domains with one additional item added to 
make the total number of the statements equal 33 (Qsample). These statements were then placed into the score sheet (Figure 1), and forced to follow a quasi-normal distribution, that is, 2-3-4-5-5-5-4-3-2. The reliability of this instrument was tested with Cronbach's alpha. Each statement was randomly assigned a number from 1 to 33 for the subjects to arrange and place into the score sheet. To get more understandability, the statements were pilottested with 25 health personnel and were then revised as appropriate before the study.

\section{Study setting}

The study was conducted in the three southernmost provinces of Thailand: Yala, Pattani, and Narathiwat, during April to October 2007. Apart from the problems of ethnic violence, the area is in a remote part of the country where the logistic problems will be easily visible. The area is also close to Malaysia, so cross-border diseases have a high chance of spread due to the movement of populations.

\section{Study subjects and procedures}

The research protocol was approved by the Ethics Committee of the Faculty of Medicine, Prince of Songkla University, prior to conducting the study. A list of all health facilities in the study area was obtained from the local health offices. Health personnel designated by each facility to be responsible for influenza pandemic preparedness were identified. These included a numbers of doctors, nurses, pharmacists, laboratory personnel, public health specialists, public health administrators, and junior health workers. All were invited to participate in the study. The selected personnel were sent a set of documents, which included a cover letter, an overview describing the study importance and objective, a set of 33 statements (Q sample), a standardized step-by-step set of instructions for responding to the study, and a score sheet. Following the initial mailing, two phases of follow up were performed: a sequence of telephone calls at one month, with nonresponders contacted by the first author after three months.

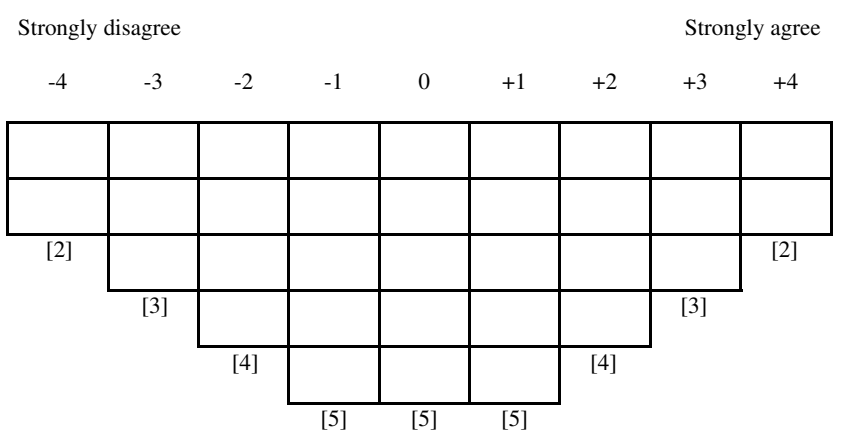

Figure I

Participant score sheet.
Each consenting subject was asked to rank the 33 statements about different issues concerned with an influenza pandemic into the levels of agreement and disagreement based on their own judgments. Each participant was requested to place two statements in the columns of strongly disagree $(-4)$ and strongly agree $(+4)$, three in disagree $(-3)$ and agree $(+3)$, four in -2 and +2 , five in -1 and +1 , and five statements in the neutral response column (0). However, if they thought that our distribution did not represent their real perceptions, they were encouraged to sort such statements accordingly. Each Q-sort was considered as complete if all 33 statements were placed into the score sheet without repetition of the statements.

\section{Data entry and analysis}

The data from each completed score sheet were entered and analyzed in PQMethod 2.11 (free software). Betweensubjects correlation matrix was computed and a Q (subject-wise) factor analysis by principle components analysis (PCA) method was performed using a varimax rotation technique. Factors that could explain more than $5 \%$ of the variance were adopted and retained into the final solution. A participant who had absolute factor loadings of larger than \pm 0.45 , which suggests high significance $(\mathrm{p}<$ 0.01 ) with the group, was included into that particular factor. In each factor, the ascending sorted normalized scores (Z-scores) of assigned number of each statement were returned into the score sheet from right to left order (Figures 2, 3, and 4). Each final score sheet thus displays the pattern of the defined factor. Comparisons among patterns were based on the factor scores and the mean values of the domain of the statements. For visualization of the patterns, the domains of each statement were linked to different colors or grey shadings in the final Q-sort models that are shown in Figures 2, 3, and 4. Since the cells in the extreme score regions reflect strong perceptions in the domains, they are the primary target for comparing similarity and dissimilarity of each group of health

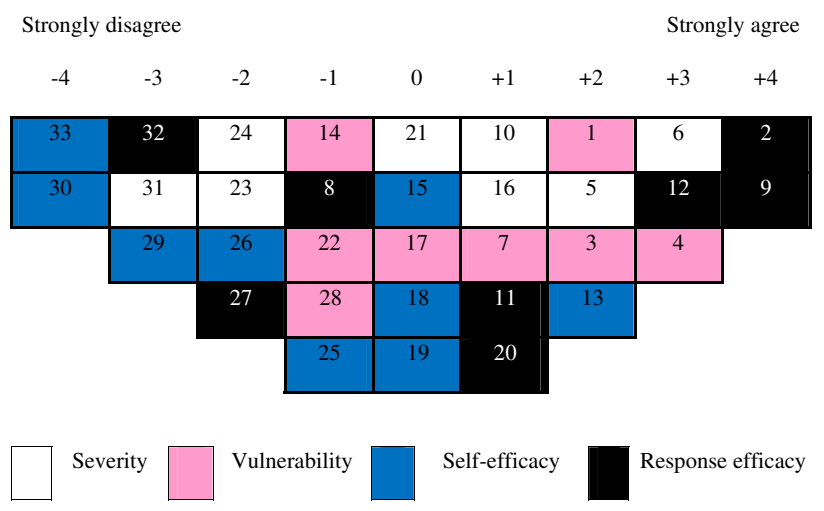

Figure 2

Pattern I. pessimistic with perceived low self-efficacy. 
Strongly disagree

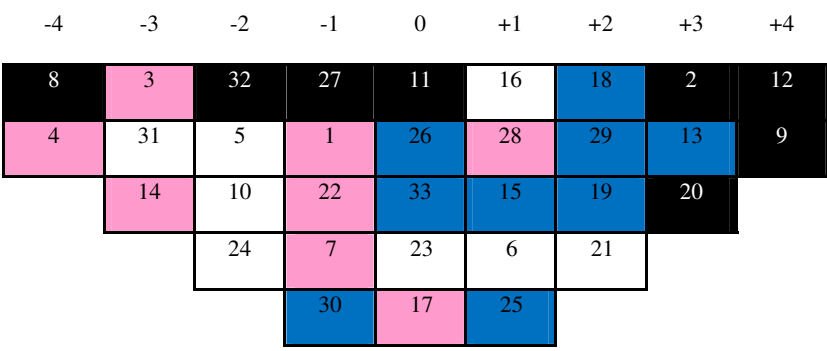

Severity
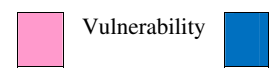

Response efficacy

Figure 3

Pattern II. optimistic with perceived low severity and low vulnerability.

personnel's perceptions on the threat of an influenza pandemic.

\section{Results}

After consultation with an expert in instrument development, 33 statements listed in Table 1 were used in the study. Although some statements may resemble others, they measure different aspects or domains on an influenza pandemic. For example, statements 3, 14, and 22 are all concerned with vulnerability (V), but measure or emphasize different aspects. Statement 3 emphasizes avian influenza, statement 14 natural and inevitable threat, and 22 on proximity to the threat. Statements 11 and 19 measure different domains of the PMT: statement 11 represents response efficacy (RE); whereas, statement 19 represents self-efficacy (SE). The subjects should perceive these statements as different questions. The overall Cronbach's alpha of this instrument was 0.70 .
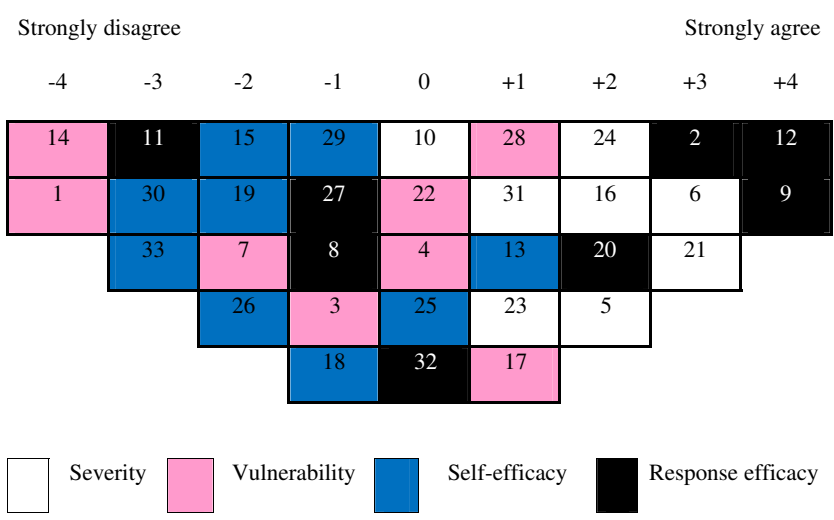

Figure 4

Pattern III. mixed with perceived low self-efficacy but low vulnerability.
Of a total 385 health personnel, 271 (70\%) persons completed the score sheet. There were no statistically significant differences between responders and non-responders in terms of gender, age, religion, educational level, total period of working, job classification, experience of getting training on influenza pandemic preparedness and perceived levels of knowledge about an influenza pandemic, public health measures against an influenza pandemic and impacts of an influenza pandemic. However, the nonresponders had a lower educational level than those of the responders (35\% vs. $18 \%$, respectively). The basic characteristics of the 271 respondents are presented in Table 2.

Q factor analysis gave three factors that met our criteria with the percentages of explained variance being $30.1 \%$, $8.7 \%$, and $5.5 \%$, respectively. After varimax rotation, 90 subjects were classified into factor I (in other words, the first pattern composites of 90 health personnel), 40 into factor II, and 62 into factor III. The other 79 subjects were not classified into any factor because all their loading values were less than 0.45 or had high loading on more than one factor. The composite reliability of each factor was 0.99, with the corresponding standard errors of factor scores being $0.05,0.08$, and 0.06 . The correlation coefficients between the three factors were 0.37 (factor I vs. II), 0.54 (factor I vs. III), and 0.55 (factor II vs. III), indicating a moderate similarity among the patterns.

The three patterns had scores for each specific statement distributed into the Q-sort model or composite factor array and are displayed in Figures 2, 3, and 4. The same information is displayed in Table 1 . Factor scores of statement 1 were $2,-1$, and -4 as shown in the first row of Table 1. In the Q-sort model, statement 1 is in column +2 of Figure 2, and column -1 of Figure 3, and column -4 of Figure 4.

From Table 1, statement number 9 has a common factor score of 4 for all three patterns. This indicates that all three patterns of health personnel strongly perceived that multimeasures must be performed during an influenza pandemic. Statement number 12 was also in columns +4 of Figures 3 and 4, and +3 of Figure 2, which is related to response efficacy on multilevels of responsibility for preparedness against the threat. In contrast, statement 4 was the most dissenting issue with factor scores of $3,-4$, and 0 . Health personnel classified as pattern I quite strongly perceived that Thailand will have possibly high impacts from an influenza pandemic if and when one occurs, but those classified in pattern II strongly disagreed, and those in the remaining group were neutral.

The right extremes of all three Q-sort models are consistently filled with three black cells (statements 2, 9, and 12) out of 5 cells of that region. This indicates that all three 
Table I: List of statements and composite factor scores by pattern

\begin{tabular}{|c|c|c|c|c|}
\hline \multirow[b]{2}{*}{ No. } & \multirow[b]{2}{*}{ Statement } & \multicolumn{3}{|c|}{ Pattern } \\
\hline & & 1 & II & III \\
\hline 1 & $\begin{array}{l}\text { I perceive that Thailand can be the source of an influenza pandemic since there are many cases of avian influenza } \mathrm{A}(\mathrm{H} 5 \mathrm{NI}) \text { in } \\
\text { both humans and poultry in many parts of the country }(\mathrm{V})\end{array}$ & 2 & -1 & -4 \\
\hline 2 & $\begin{array}{l}\text { I perceive that influenza pandemic preparedness has short and long terms benefits in reducing the impacts of an influenza } \\
\text { pandemic, as well as the other emerging infectious diseases (RE) }\end{array}$ & 4 & 3 & 3 \\
\hline 3 & $\begin{array}{l}\text { I perceive that there is a high possibility of an occurrence of the next influenza pandemic since there are many cases of avian } \\
\text { influenza } A(H 5 N I) \text { in humans and poultry in many parts of the world }(\mathrm{V})\end{array}$ & 2 & -3 & -1 \\
\hline 4 & I perceive that Thailand will be affected greatly by an influenza pandemic if and when it occurs ( $V)$ & 3 & -4 & 0 \\
\hline 5 & I perceive that an influenza pandemic can cause significant pressure on health care services for several months $(S)$ & 2 & -2 & 2 \\
\hline 6 & I perceive that an influenza pandemic will cause enormous economic loss (S) & 3 & I & 3 \\
\hline 7 & I perceive that the occurrence of an influenza pandemic cannot be predicted $(\mathrm{V})$ & I & -1 & -2 \\
\hline 8 & $\begin{array}{l}\text { I perceive that public health measures (e.g., surveillance, infection control, isolation and quarantine, etc.) have no efficiency in } \\
\text { reducing the impacts of an influenza pandemic (RE) }\end{array}$ & -1 & -4 & -1 \\
\hline 9 & $\begin{array}{l}\text { I perceive that multi-measures (pharmaceutical and non-pharmaceutical) must be performed during an influenza pandemic } \\
\text { event to reduce the impacts (RE) }\end{array}$ & 4 & 4 & 4 \\
\hline 10 & I perceive that an influenza pandemic can causes excess of illnesses, hospitalizations and deaths $(S)$ & I & -2 & 0 \\
\hline 11 & I perceive that antiviral drugs are efficient at reducing the impacts of an influenza pandemic (RE) & I & 0 & -3 \\
\hline 12 & $\begin{array}{l}\text { I perceive that efficient influenza pandemic preparedness is the responsibility of every level from national to community both } \\
\text { governmental and private sectors, in order to reduce its impacts. (RE) }\end{array}$ & 3 & 4 & 4 \\
\hline 13 & $\begin{array}{l}\text { I have confidence that public health measures (e.g., surveillance, infection control, isolation and quarantine, etc.) are efficient in } \\
\text { reducing the impacts of an influenza pandemic (SE) }\end{array}$ & 2 & 3 & 1 \\
\hline 14 & I perceive that an influenza pandemic is an inevitable natural health threat $(\mathrm{V})$ & -1 & -3 & -4 \\
\hline 15 & I have confidence that vaccination measures can reduce the impacts of an influenza pandemic (SE) & 0 & 1 & -2 \\
\hline 16 & I perceive that when an influenza pandemic occurs, it will affect all countries around the globe. (S) & I & I & 2 \\
\hline 17 & I perceive that everyone has a high chance to be infected with the virus when a pandemic occurs $(\mathrm{V})$ & 0 & 0 & I \\
\hline 18 & I have confidence that local health personnel have the capacity to control an influenza pandemic and reduce its impact (SE) & 0 & 2 & -1 \\
\hline 19 & I have confidence that antiviral drug measure can reduce the impacts of an influenza pandemic (SE) & 0 & 2 & -2 \\
\hline 20 & $\begin{array}{l}\text { I perceive that performing multi-measures (pharmaceutical and non-pharmaceutical) during an influenza pandemic event can } \\
\text { reduce the impacts (RE) }\end{array}$ & I & 3 & 2 \\
\hline 21 & I perceive that an influenza pandemic can causes a very high health care cost (S) & 0 & 2 & 3 \\
\hline 22 & I perceive that our world is now close to the next influenza pandemic $(\mathrm{V})$ & -1 & -1 & 0 \\
\hline 23 & $\begin{array}{l}\text { I perceive that if an influenza pandemic occurs, every community has to rely on its own resources (help cannot be easily shifted } \\
\text { from one community to another), it is not like other natural health threats }(S)\end{array}$ & -2 & 0 & I \\
\hline 24 & I perceive that an influenza pandemic can cause great psychosocial disruption (S) & -2 & -2 & 2 \\
\hline 25 & I have confidence that I can get influenza vaccines and antiviral drugs when an influenza pandemic occurs (SE) & -1 & I & 0 \\
\hline 26 & I have confidence that Thailand has the chance to use vaccines and antiviral drugs when an influenza pandemic occurs (SE) & -2 & 0 & -2 \\
\hline 27 & I perceive that influenza vaccines have the highest efficiency in reducing the impacts of an influenza pandemic (RE) & -2 & -1 & -1 \\
\hline 28 & $\begin{array}{l}\text { I perceive that increasing globalization (transportation, communication, urbanization) can cause the rapid spread of an influenza } \\
\text { pandemic }(\mathrm{V})\end{array}$ & -1 & I & I \\
\hline 29 & I have confidence that Thailand can control an influenza pandemic if and when it occurs (SE) & -3 & 2 & -1 \\
\hline 30 & $\begin{array}{l}\text { I have confidence that influenza vaccines and antiviral drugs will be enough provided for everyone if and when an influenza } \\
\text { pandemic occurs (SE) }\end{array}$ & -4 & -1 & -3 \\
\hline 31 & I perceive that an influenza pandemic will cause a great productivity loss $(\mathrm{S})$ & -3 & -3 & I \\
\hline 32 & I perceive that influenza vaccines are cost-effective in reducing the impacts of an influenza pandemic (RE) & -3 & -2 & 0 \\
\hline 33 & I have confidence that local health personnel can control an influenza pandemic if and when it occurs (SE) & -4 & 0 & -3 \\
\hline
\end{tabular}

$\mathrm{S}=$ severity, $\mathrm{V}=$ vulnerability, $\mathrm{RE}=$ response efficacy, $\mathrm{SE}=$ self-efficacy groups of health personnel have strong perception on response efficacy of the control measures rather than on the other domains. The left extremes of those three patterns, on the other hand, contain different mixtures for different patterns. Health personnel classified into pattern I were pessimistic. They had negative perceptions of selfefficacy as there are three blue or dark grey cells (statements 33, 30, and 29) in the columns of -4 and -3 . Health personnel classified into pattern III were less extreme about this, but still have two blue (dark grey) cells (state- ments 30 and 33) in the -3 column. None of the blue cells (dark gray in black-and-white printing) are present in the left extreme regions of the pattern II indicating optimism of the group of personnel.

Means of factor scores for each component of the PMT are displayed in Table 3. All groups had positive perceived response efficacy of the measures. Patterns I and III, however, perceived low self-efficacy, in contrast to high perceived self-efficacy of pattern II. 
Table 2: Basic characteristics of the respondents

\begin{tabular}{|c|c|c|}
\hline Variable & Number $(n=27 I)$ & $\%$ \\
\hline \multicolumn{3}{|l|}{ Sex } \\
\hline Male & 148 & 54.6 \\
\hline Female & 123 & 45.4 \\
\hline Age Mean(SD) & $37.4(8.3)$ & \\
\hline \multicolumn{3}{|l|}{ Job classification } \\
\hline Public health specialist & 92 & 33.9 \\
\hline Public health administrator & 51 & 18.8 \\
\hline Junior health worker & 50 & 18.4 \\
\hline Nurse & 39 & 14.4 \\
\hline Doctor & 14 & 5.2 \\
\hline Pharmacist & 11 & 4.1 \\
\hline Laboratory personnel & 9 & 3.3 \\
\hline Other & 5 & 1.8 \\
\hline \multicolumn{3}{|l|}{ Educational level } \\
\hline Lower than bachelor degree (certificate) & 48 & 17.7 \\
\hline Bachelor degree & 202 & 74.5 \\
\hline Higher than bachelor degree & 21 & 7.8 \\
\hline \multicolumn{3}{|l|}{ Place of work } \\
\hline Provincial public health office & 8 & 3.0 \\
\hline Hospital & 76 & 28.0 \\
\hline District public health office & 58 & 21.4 \\
\hline Health center & 129 & 47.6 \\
\hline
\end{tabular}

Optimistic personality of pattern II was also expressed as perception of low severity and low vulnerability where the pattern I has isolated neutral perception of severity with a moderate level of perceived vulnerability. Finally, more mixed appraisal is found in pattern III, the group who perceived a low level of vulnerability but a very high level of severity.

\section{Discussion}

We identified three main patterns of health personnel in southern Thailand based on the perception toward a threat of an influenza pandemic. Pattern I was pessimistic (strongly perceived response efficacy, but perceived low self-efficacy). Pattern II was optimistic (strongly perceived response efficacy, but perceived low severity and low vulnerability). Pattern III was mixed (strongly perceived response efficacy, but perceived low vulnerability and low self-efficacy). A high perception on response efficacy was

Table 3: Mean factor scores of each component of the PMT by pattern

\begin{tabular}{lccc}
\hline & \multicolumn{3}{c}{ Pattern } \\
\cline { 2 - 4 } Component & $\begin{array}{c}\text { Pessimistic } \\
(\mathrm{n}=90)\end{array}$ & $\begin{array}{c}\text { Optimistic } \\
(\mathrm{n}=40)\end{array}$ & $\begin{array}{c}\text { Mixed } \\
(\mathrm{n}=62)\end{array}$ \\
\hline Perceived severity & 0 & -0.62 & 1.75 \\
Perceived vulnerability & 0.62 & -1.50 & -1.12 \\
Perceived response efficacy & 0.87 & 0.87 & 1 \\
Perceived self-efficacy & -1.33 & 1.11 & -1.44 \\
\hline
\end{tabular}

predominantly found in all health personnel groups. Perceptions on vulnerability were more varied.

The majority of our health personnel perceived low selfefficacy toward an influenza pandemic. Self-efficacy is one important component of coping appraisal of the PMT [19]. It has powerful influence on human's feeling, thinking, motivation, and behavior [20-22]. Previous metaanalyses provided evidence for self-efficacy having the largest effect size and was the strongest predictions of protection motivation $[23,24]$. People with low self-efficacy usually believe that tasks are harder than they can handle. This can lead to limit task planning, increase stress, reduce the low level of attempt, and having a tendency to avoid duties and activities [20-22]. Balicer et al. reported that nearly a half of local health workers may be unwilling to report to duty during a pandemic event [9]. However, that study did not identify different patterns of health workers as our study has done. Another conventional survey conducted among a general population (rather than health workers) in developed countries of Europe and Asia on avian influenza risk perception showed a similar result. The level of self-efficacy among the respondents was also low and the authors concluded that a low level of self efficacy may obstruct any interventions [25].

The most dissenting issue among our health personnel toward this threat was on vulnerability of possible impacts in the country (statement number 4). Naturally, the occurrence and severity of an influenza pandemic cannot be predicted [26]. Fifteen per cent of our health per- 
sonnel perceived the threat to have low severity and low vulnerability. In other words, this group of health personnel was optimistic that such a threat would not severely affect people's lives. A small survey by Curtis et al. on the perceptions toward such a threat among physicians showed that more than half did not consider that the risk of an imminent influenza pandemic was more than a possibility [10]. Both perceived severity and perceived vulnerability are components of threat appraisal of the PMT [19]. Perception of low level of severity and vulnerability or low levels of appraised threat of an influenza pandemic may inhibit motivation of health personnel to engage in protective behavior $[27,28]$. However, the effect sizes of such two components in previous meta-analyses were small to medium and barely predicted of protection motivation and behavior compared to the components of coping appraisal (response efficacy and self-efficacy) [23,24].

Perception of response efficacy was stronger than other domains. This may be influenced by past experiences of the country, which after employing on multi-sectors and multi-measures could successfully suppress avian influenza A(H5N1) [29].

This study used a wide range of front-line health personnel responsible for influenza pandemic preparedness. Thus, it may reflect the problems specific to this area with acceptable accuracy. The study was confined to the three southernmost provinces of Thailand where avian influenza A (H5N1) has never occurred. Our study subjects might be different from those in other regions of the country where the infected cases of that avian influenza in both humans and poultry have been reported, and intensive avian influenza controls have been fully activated. The study subjects were also predominated by personnel from health centers and community hospitals in rural areas. The threat of a pandemic may be less compared to in urban areas. The study was based on Q methodology which had never been employed among local health workers; thus, the data have to be interpreted with caution. Approximately $30 \%$ of the respondents were not able to be classified into any of the three groups determined by our factor analysis. The patterns are therefore far from ideal. The statements about influenza pandemic that were used in our study should be improved to be more specific for health workers in future work.

\section{Conclusion}

Despite the above limitations, this study highlights important findings. Strong consistent perceptions of implementing recommended measures against an influenza pandemic can remove or mitigate impacts of this threat, and may suggest a low priority to convince health personnel on the efficacy of the measures. Perception of low self-efficacy in certain subgroups who gave low scores on the statements related to self-efficacy on an influenza pandemic indicates the need to improve self-confidence of health personnel to participate in an emergency response by the control program.

\section{Competing interests}

The authors declare that they have no competing interests.

\section{Authors' contributions}

TP designed this study, was the principal investigator of the project, performed data analysis, and drafted the manuscript. VC provided supervision, suggestion, and development on manuscript writing. All authors have contributed to revision of the draft version and have read and accepted the final version of this manuscript.

\section{Acknowledgements}

This study was part of the first author's thesis to fulfill the requirement for $\mathrm{PhD}$ in Epidemiology at Prince of Songkla University (PSU). We sincerely acknowledge all health personnel who participated in the study. Appreciative thanks to the Graduate School, PSU, and the Disease Control Department, Ministry of Public Health, Thailand for supporting the study. We also wish to thank Dr. Alan Geater, Dr. Vorasit Sornsrivichai, Mr. Edward McNeil, the Epidemiology Unit, Faculty of Medicine, PSU, and Mr. Darrell Beng, Adelaide, South Australia.

\section{References}

I. Potter CW: A history of influenza. J Appl Microbiol 200I, 91:572-579.

2. Whitley RJ, Monto AS: Seasonal and pandemic influenza preparedness: a global threat. J Infect Dis 2006, 194(Suppl 2):65-69.

3. Kilbourne ED: Influenza pandemics of the 20th century. Emerg Infect Dis 2006, I 2:9-14.

4. Webby RJ, Webster RG: Are we ready for pandemic influenza? Science 2003, 302:1519-1522.

5. Stohr K, Esveld M: Will vaccines be available for the next influenza pandemic? Science 2004, 306:2195-2196.

6. Lau JTF, Tsui $H$, Lau M, Yang X: SARS transmission, risk factors, and prevention in Hong Kong. Emerg Infect Dis 2004, 10:587-592.

7. Lau JTF, Yang X, Pang E, Tsui $H$, Wong E, Wing YK: SARS-related perceptions in Hong Kong. Emerg Infect Dis 2005, I I:417-424.

8. Lau JTF, Yang X, Tsui $\mathrm{H}$, Kim JH: Monitoring community responses to the SARS epidemic in Hong Kong: from day 10 to day 62. J Epidemiol Community Health 2003, 57:864-870.

9. Balicer RD, Omer SB, Barnett DJ Jr, Everly GS: Local public health workers' perceptions toward responding to an influenza pandemic. BMC Public Health 2006, 6:99.

10. Curtis N, Pollard AJ: Physicians' perception of pandemic influenza. Arch Dis Child 2007, 92:938.

II. Imai T, Takahashi K, Todoroki M, Kunishima H, Hoshuyama T, Ide R, Kawasaki T, Koyama N, Endo K, Fujita H, et al.: Perception in relation to a potential influenza pandemic among healthcare workers in Japan: implications for preparedness. J Occup Health 2008, 50:13-23.

12. Wong TY, Koh GC, Cheong SK, Lee HY, Fong YT, Sundram M, Koh K, Chia SE, Koh D: Concerns, perceived impact and preparedness in an avian influenza pandemic - a comparative study between healthcare workers in primary and tertiary care. Ann Acad Med Singapore 2008, 37:96-102.

13. Putthasri W, Lertiendumrong J, Chompook $P$, Tangcharoensathien $V$, Coker R: Capacity of Thailand to contain an emerging influenza pandemic. Emerg Infect Dis 2009, 15:423-432.

14. Watts S, Stenner P: Doing Q methodology: theory, method and interpretation. Qual Res Psychol 2005, 2:67-91.

15. Brown SR: A primer on $\mathbf{Q}$ methodology. Operant Subjectivity 1993, 16:91-138. 
16. McKeown BF, Thomas DB: $Q$ Methodology Newbury Park: Sage Publications; 1988.

17. Amin Z: $\mathbf{Q}$ methodology-a journey into the subjectivity of human mind. Singapore Med / 2000, 4I:4I0-4|4.

18. Valenta AL, Wigger U: $\mathbf{Q}$ methodology: definition and application in health care informatics. J Am Med Inform Assoc 1997, 4:50I-5I0.

19. Rogers RW: Cognitive and physiological processes in fear appeals and attitude change: a revised theory of protection motivation. In Social Psychophysiology: A Sourcebook Edited by: Cacioppo JT, Petty RE. New York: Guilford Press; 1983:153-176.

20. Bandura A: Self-efficacy: toward a unifying theory of behavioral change. Psychol Rev 1977, 84:191-215.

21. Bandura A: Human agency in social cognitive theory. Am Psychol 1989, 44: I I75-I I84.

22. Bandura A: Self-efficacy: The Exercise of Control New York: Cambridge University Press; 1995.

23. Floyd DL, Prentice-Dunn S, Rogers RW: A meta-analysis of research on protection motivation theory. J Appl Soc Psychol 2000, 30:407-429.

24. Milne S, Sheeran P, Orbell S: Prediction and intervention in health-related behavior: a meta-analytic review of protection motivation theory. J Appl Soc Psychol 2000, 30: 106-I 43.

25. de Zwart O, Veldhuijzen IK, Elam G, Aro AR, Abraham T, Bishop GD Richardus JH, Brug J: Avian influenza risk perception, Europe and Asia. Emerg Infect Dis 2007, 13:290-293.

26. Blaser MJ: Pandemics and preparations. J Infect Dis 2006, 1 94(Suppl 2):70-72.

27. Boer H, Seydel ER: Protection motivation theory. In Predicting Health Behaviour Edited by: Conner M, Norman P. Buckingham: Open University Press; 1996:95-120.

28. Rippetoe PA, Rogers RW: Effects of components of protection motivation theory on adaptive and maladaptive coping with a health threat. J Pers Soc Psychol 1987, 52:596-604.

29. Barnett DJ, Balicer RD, Lucey DR Jr, Everly GS, Omer SB, Steinhoff MC, Grotto I: A systematic analytic approach to pandemic influenza preparedness planning. PLoS Med 2005, 2:e359.

\section{Pre-publication history}

The pre-publication history for this paper can be accessed here:

http://www.biomedcentral.com/1471-2458/9/161/pre

pub
Publish with Bio Med Central and every scientist can read your work free of charge

"BioMed Central will be the most significant development for disseminating the results of biomedical research in our lifetime. "

Sir Paul Nurse, Cancer Research UK

Your research papers will be:

- available free of charge to the entire biomedical community

- peer reviewed and published immediately upon acceptance

- cited in PubMed and archived on PubMed Central

- yours - you keep the copyright
BioMedcentral 